OPEN ACCESS

Edited by: Clare Heyward,

Arctic University of Norway, Norway

Reviewed by:

Jacopo Giuntoli, Independent Researcher, Montecatini Terme, Italy Simon Haikola,

Linköping University, Sweden

${ }^{*}$ Correspondence: James Palmer james.palmer@bristol.ac.uk

Specialty section: This article was submitted to Negative Emission Technologies, a section of the journal

Frontiers in Climate

Received: 08 March 2021 Accepted: 17 May 2021 Published: 10 June 2021

Citation:

Palmer J and Carton W (2021) Carbon Removal as Carbon Revival? Bioenergy, Negative Emissions, and the Politics of Alternative Energy Futures. Front. Clim. 3:678031. doi: 10.3389/fclim.2021.678031

\section{Carbon Removal as Carbon Revival? Bioenergy, Negative Emissions, and the Politics of Alternative Energy Futures}

\author{
James Palmer ${ }^{1 *}$ and Wim Carton ${ }^{2}$ \\ ${ }^{1}$ School of Geographical Sciences, University of Bristol, Bristol, United Kingdom, ${ }^{2}$ Lund University Center for Sustainability \\ Studies, Lund, Sweden
}

Conscious of the need to limit climate warming to 1.5 degrees, many countries are pinning their hopes upon carbon dioxide $\left(\mathrm{CO}_{2}\right)$ removal through the industrial-scale combination of bioenergy with carbon capture and storage (BECCS). But it is not merely by storing captured $\mathrm{CO}_{2}$ that BECCS enthusiasts hope to harness biomass combustion for climate repair. Increasingly, more productive and ostensibly profitable uses for captured $\mathrm{CO}_{2}$ are also being identified. The concept of BECCS is evolving, in other words, into "BECCUS" - bioenergy with carbon capture, utilisation and storage. Against this backdrop, this Perspective sets out two main arguments. Firstly, regardless of the precise use to which captured $\mathrm{CO}_{2}$ is put, efforts to predicate large-scale negative emissions upon biomass combustion should in our view be understood as attempts to reconfigure the fundamental relationship between climate change and energy use, turning the latter from a historical driver of climate warming into a remedial tool of climate repair. Secondly, the emergence of BECCUS cannot be understood solely as an attempt to make bioenergy-based negative emissions more economically viable. At stake, rather, are conflicting ideas about the role that intensive energy use should play in future global sustainable development pathways. This Perspective therefore calls for governance frameworks for carbon dioxide removal to adjudicate between conflicting approaches to achieving negative emissions not only on the basis of technical efficiency, or even "on-the-ground" social and environmental impacts, but also according to compatibility with socially legitimate visions and understandings of what energy - and more specifically energy use-should ultimately be for in the post-fossil fuel era.

Keywords: carbon dioxide removal, bioenergy, BECCS, energy consumption, negative emissions technologies, carbon utilisation and storage, social legitimacy

\section{BIOENERGY WITH CARBON CAPTURE AND STORAGE: HARNESSING PLANT WORK FOR CLIMATE REPAIR?}

As scenarios for avoiding dangerous climate warming increasingly come to hinge upon achieving massive quantities of negative greenhouse gas (GHG) emissions, many countries are pinning their hopes upon BECCS - the industrial-scale combination of bioenergy generation with carbon capture and storage technology - as a means of removing carbon dioxide from the atmosphere. 
Not formally acknowledged by the Intergovernmental Panel on Climate Change (IPCC) until 2007, BECCS is now a linchpin of almost all IPCC emissions scenarios aiming to limit climate warming to no more than 1.5 degrees Celsius above preindustrial levels, and features in the majority of scenarios aiming to cap warming at 2 degrees as well (IPCC, 2014, 2018) ${ }^{1}$. On the surface, the core appeal of BECCS appears to reside in its reliance upon carbon sequestration processes already found in nature. Since vegetal lifeforms absorb carbon dioxide through photosynthesis as they grow, burning biomass fuels derived from trees and other plants theoretically adds less carbon dioxide to the atmosphere than burning fossil fuels instead. Research examining real-world bioenergy production, however, has raised significant concerns about the relative inefficiency of biomass burning when compared to coal, not to mention the long timescales often required for plant growth to cancel out combustion emissions in practice (Searchinger et al., 2018) ${ }^{2}$. Against this backdrop, the chief appeal of BECCS-we argue-lies not in its reliance upon the photosynthetic work of plants, but rather in its potential to help defuse controversy over the sometimes significant climate change impacts of "conventional" bioenergy production, by rendering biomass burning not just theoretically carbon neutral, but carbon negative.

Reports published by the Committee on Climate Change (2019) and the Royal Society and Royal Academy of Engineering (2018) suggest that BECCS could allow the UK to remove tens of millions of tonnes of carbon dioxide from the atmosphere annually over the coming decades. Theoretically at least, the UK already generates sufficient bioenergy for BECCS to be deployed on this scale-indeed, the country currently burns sufficient biomass fuel to emit more than 15 million tonnes of biogenic carbon dioxide annually (ONS, 2019). Yet to date, actual implementation of BECCS as a fully-fledged combination of biomass burning and carbon capture and storage technology has been modest. In early 2019, for example, Drax power stationthe UK's largest piece of electricity-generating infrastructurebecame the first such facility in the world to trial the capture of carbon dioxide emissions generated exclusively from the burning of biomass fuel. Only approximately one tonne of carbon dioxide per day was captured during this trial, however, and even then only temporarily (Drax Group plc, 2019a) ${ }^{3}$. In part, this discrepancy can be traced to the high existing costs of technologies designed to extract carbon dioxide from power station flue gases. But putting in place the necessary infrastructures to achieve the safe, long-term storage of captured $\mathrm{CO}_{2}$, especially at scale, also remains a significant economic and

\footnotetext{
${ }^{1}$ According to Chatham House (2020, p. 5), more than 100 of 116 scenarios for limiting global warming to $<2$ degrees, as set out by the IPCC (2014) in its fifth assessment report, relied upon negative GHG emissions, with BECCS being responsible on average for c.12Gt of $\mathrm{CO}_{2}$ removals annually by 2100 . See also Smith and Porter (2018).

${ }^{2}$ In February 2021 more than 500 scientists signed a letter to five major world leaders calling for an end to subsidies for burning wood from forests (van Ypersele, 2021).

${ }^{3}$ More recently, Drax have partnered with Mitsubishi Heavy Industries to undertake a further 12 month trial, albeit aiming to capture just $300 \mathrm{~kg}$ of $\mathrm{CO}_{2}$ per day (Drax Group plc, 2020a).
}

policy challenge (see Scott et al., 2013; Durmaz, 2018). Viewing these issues together, the prospects for achieving genuinely largescale BECCS, at least in the near future, seem somewhat bleak.

Despite these obstacles, powerful stakeholders in the UK energy sector continue to attach significant aspirations to biomass combustion as the basis for large-scale carbon dioxide removal. Moreover, it is not merely by storing captured carbon dioxide-for instance in former oil and gas fields-that these stakeholders hope to harness the work of plants as a largescale basis for meaningful climate repair. Increasingly, a range of more productive and ostensibly profitable end uses for that $\mathrm{CO}_{2}$-whether for enhancing horticultural yields, for producing synthetic feedstocks for fisheries and livestock, or even for manufacturing new forms of bioplastic (see for example Drax Group plc, 2018)-are also being identified. The concept of BECCS is hence evolving, at least in the hands of some energy actors, into "BECCUS" - bioenergy with carbon capture, utilisation and storage. In the context of these developments, this Perspective aims to set out two main arguments. Firstly, regardless of the precise use to which captured $\mathrm{CO}_{2}$ is eventually put, efforts to predicate large-scale negative emissions upon biomass combustion should in our view be understood as attempts to reconfigure the fundamental relationship between climate change and energy use, turning the latter from a historical driver of climate warming into a remedial tool of climate repair. Secondly, and building on this first point, ongoing efforts on the part of some groups to advocate BECCUS (and not just BECCS) cannot be understood simply as a move intended to make bioenergy-based negative emissions more economically viable. At stake, rather, are fundamentally conflicting ideas about the role that intensive energy use-and indeed resource consumption more broadly - should play in shaping future global sustainable development pathways. As a result, we argue, it is vital that governance frameworks for carbon dioxide removal today devise means of adjudicating between conflicting approaches to achieving negative emissions not only on the basis of their technical efficiency, or even their "on-the-ground" social and environmental impacts, but also according to their compatibility with socially legitimate visions and understandings of what energy - and more specifically energy use-should ultimately be for in the post-fossil fuel era. While our argument mainly draws on examples from the UK, the concerns we identify should be of relevance to BECCS policy discussions in other contexts as well.

\section{FANNING THE FLAMES: THE "FOSSIL INHERITANCE" OF BECCS}

On its own terms, bioenergy's climate credentials hinge upon the vital capacities of trees and other plants to continually "remake themselves out of simple substances that are present in their surroundings" (Lenton and Latour, 2018, p. 1067). Unlike fossil fuels-derived from carbon dioxide absorbed by prehistoric plants (Sieferle, 2001) - biomass fuels are assembled through the photosynthesis of plants alive today, out of molecules which were already present in the atmosphere. For many protagonists of "natural climate solutions" such as afforestation 
or peatland restoration, these vital capacities of plants should be sufficient to achieve large-scale carbon dioxide removal by themselves. Yet, while the question of how best to expand the size of the earth's "natural" carbon sinks is the subject of fervent scientific and policy attention (Griscom et al., 2017; Moomaw et al., 2019; Cook-Patton et al., 2020) such sinks are not without weaknesses, including their susceptibility to environmental change and disruption (such as forest fires) and their potential to become saturated over time (Seidl et al., 2014; Hubau et al., 2020). Assessments of the potential benefits of combining bioenergy with man-made carbon capture and storage technology, accordingly, have long pointed to these innate limits to vegetal capacities to achieve long-term carbon storage (see e.g., Obersteiner et al., 2002), even as they depend critically upon plants and trees' ongoing carbon absorption.

Despite a commonplace view of bioenergy as "decarbonisation" tool ${ }^{4}$, it is more accurate to describe the replacement of fossil fuels with biomass fuels as a means of recarbonising incumbent energy systems. Relying on plants does not eradicate carbon from our energy systems, but simply alters the geographies and temporalities of carbon metabolism upon which those systems are based. To be sure, the practices through which biomass fuels are produced are radically different from the large-scale coal mining and other extractive activities associated with fossil fuels. In the space of a little over 10 years, for example, large-scale electricity generation facilities in the UK have become dependent upon the productivity of commercially-managed forests in places as disparate as the southern United States, Canada and Russia (USDA Foreign Agricultural Service, 2019; Palmer, 2021). Within the UK's road transport sector, meanwhile, hundreds of millions of litres of liquid biofuels are now blended into petrol and diesel each year, having started life initially as sugar cane growing in Brazil, corn cultivated in Ukraine, or even used cooking oil imported from China (UK DfT, 2020). Yet, despite the stark contrast with fossil fuel supply chains, such efforts to expand bioenergy use-whether coupled to carbon capture and storage facilities or not-inevitably act to perpetuate, rather than disrupt, the centuries-long practise of deriving energy from large-scale hydrocarbon combustion (Lohmann, 2021).

What is unique about BECCS specifically is its potential to turn this shared pyrogenic basis of fossil energy and bioenergy from a potential weakness-after all, GHG emissions are an inevitable consequence of both forms of combustioninto a strength. On this basis, efforts to couple large-scale bioenergy generation with carbon capture and storage facilities can be viewed as enrolling plants not only as a renewable, purportedly sustainable alternative to fossil fuels, but also as a means of reconfiguring the relationship between climate change and energy use itself. In promising to recalibrate largescale hydrocarbon burning for energy around plants and to capture and safely store associated carbon dioxide emissions underground, the concept of BECCS raises the prospect-even if highly optimistic-that large scale energy consumption can

\footnotetext{
${ }^{4}$ For a notable example of the establishment of a strong link between biomass combustion and "decarbonization," see Drax Group plc (2020c).
}

be effectively transformed from a key historical driver of global climate warming into its polar opposite: a vital tool for climate repair. Viewed from such a favourable vantage point, a significant expansion of biomass burning could theoretically become a basis for decoupling energy generation from climate change not by making greater use of plants and trees as carbon sinks, butsomewhat paradoxically_by pressing plants and trees more intensively into service as bona fide producers of larger and larger quantities of carbon dioxide emissions.

As counterintuitive as this use of biomass burning as an environmental curative might seem, much of its appeal can be traced to its strong compatibility with deeply-ingrained, familiar understandings of the linkages between intensive energy consumption on the one hand, and economic development and growth (themselves understood colloquially as key markers of human progress) on the other. As critical energy scholar Daggett (2019) has recently shown, modern conceptions of energy are inextricably bound up with the laws of thermodynamics-a thoroughly nineteenth-century, north-west European science which served not only to optimise the use of fossil fuels and hence to kickstart the industrial revolution, but also to justify the increasingly efficient and productive use of those same fuels as a moral obligation, and means by which standards of living and economic development could-allegedly at least-be raised far beyond the bounds of north-west Europe itself. That energy consumption is commonly associated with development and progress today thus owes far less to the innate "nature" of energy itself, than it does to the specific political-economic context-one of fervent, fossil fuel-powered European industrial intensification and imperial expansion-within which thermodynamics was born. Moreover, and as we will argue in the next section, far from challenging these ideas, dominant visions of BECCS in the UK today serve to reinforce a view of large-scale hydrocarbon burning as both a key driver of economic growth and a moral obligation-albeit now an obligation centred not around the abstract imperative of human "progress" per se, but the rather more concrete objective of climate repair.

\section{BECCUS: "TURNING POLLUTION INTO POSSIBILITIES"? ${ }^{5}$}

Once enrolled within efforts to achieve large-scale BECCS, plants are relieved of the burden of keeping carbon dioxide permanently locked up in terrestrial landscapes, and required simply to perform the rapid, large-scale production of combustible hydrocarbon fuels. Indeed, by capturing and storing biomass combustion emissions underground, man-made technologies promise to augment the capacities of "natural" carbon sinks by keeping $\mathrm{CO}_{2}$ out of the atmosphere for far longer periods of time than any perennial plant or tree, particularly one struggling to adapt to a changing climate, would be able to do. In the $\mathrm{UK}$, the actual realisation of large-scale BECCS to date has been stymied by significant costs associated both with capturing $\mathrm{CO}_{2}$ and with developing infrastructures capable of achieving its safe,

${ }^{5}$ The phrase "turning pollution into possibilities" is derived from Drax Group plc (2018). 
long-term storage. Recent research, moreover, has pointed to considerable expert "dissatisfaction" with a continuing tendency for BECCS to be presented as a viable carbon dioxide removal strategy at large scales (Hansson et al., 2021), as well as to divergent stakeholder interpretations of what it might mean to incentivise BECCS responsibly in practice (Bellamy et al., 2021). Nonetheless, for one influential contingent of UK-based industry organisations, scientific researchers and start-up firms, concerns about BECCS can be overcome by treating $\mathrm{CO}_{2}$ not as a waste product per se, but as a valuable economic resource in its own right. This is the idea, in short, of bioenergy with carbon capture, utilisation and storage (BECCUS)-instead of waiting for long-term $\mathrm{CO}_{2}$ storage to become more profitable on its own terms, why not turn emissions themselves into products and commodities for which there is already an established economic demand?

Efforts to make use of captured carbon dioxide as a raw material for other forms of commodity production are certainly in their infancy. For example, energy firm NRG's recent manufacture of footwear from captured $\mathrm{CO}_{2}$ generated just five pairs of what it called the "shoe without a footprint" (Varinsky, 2016). Yet the ambitions which key energy stakeholders in the UK are attaching to BECCUS today are nonetheless soaring. Pointing to research which converted captured $\mathrm{CO}_{2}$ into a sustainable alternative to conventional concrete, for example, Drax Group plc (2018) - the UK's largest producer of energy from biomass burning-recently suggested that "if the shoes people walk around on can be made from captured carbon, so can the cities they walk within" (see also Foulsham, 2016). No less far-reaching, meanwhile, are aspirations attached by Drax to its partnership with start-up firm Deep Branch Biotechnology, whose proposed use of captured $\mathrm{CO}_{2}$ to produce synthetic fish and animal feed aims not only to reduce emissions from the global agricultural and fisheries sectors, but also to "help meet the anticipated increase in global demand for meat products" (Drax Group plc, 2019b). The full possibilities for BECCUS could even extend, at least in theory, to recycling captured biogenic carbon dioxide into synthetic alternatives to crude oil or gas (Jiang et al., 2010)-hypothetically enabling plants to serve not just as bioenergy resources, but also as the basis for producing man-made alternatives to fossil fuels as well, for use for example in the global aviation sector. The contrast between the scope of some of these future visions and the actual reach of BECCUS as a real-world technology today is stark-actual applications of $\mathrm{CO}_{2}$ captured from biomass burning in the UK, for example, have to date been limited largely to boosting yields in the horticultural sector (Ecofys, 2017). Nonetheless, it is significant that active investment into research and development related to combining bioenergy with carbon capture and utilisation is being spearheaded by some of the country's most influential energy stakeholders, and indeed its largest current provider of biomass-based electricity.

One immediately obvious concern that can be raised about BECCUS, of course, is whether carbon dioxide emissions put to use as the basis for commodity production can really be said to be entering long-term storage at all. Certainly if incorporated into sustainable construction materials, captured $\mathrm{CO}_{2}$ ought to remain locked up in the built environment for many decades at least, if not centuries. When used as a basis for producing synthetic animal feed or even synthetic fuels, however, the upshot of BECCUS is not strictly to keep captured $\mathrm{CO}_{2}$ out of the atmosphere, so much as to replace existing uses of GHG emissions-generating resources in other economic sectors. In short, for the carbon accounting calculations to yield a negative bottom line, assumptions must inevitably be made about the degree to which products arising from BECCUS genuinely do substitute existing resource uses in other sectors (as opposed to merely adding to them), as well as about the lengths of time for which captured $\mathrm{CO}_{2}$ remains out of atmospheric circulation. Far from seeing these assumptions as fatal flaws in the logic of BECCUS, however, we suggest that one of the key attractions of BECCUS for influential energy stakeholders in the UK today is precisely its ambiguity about the boundaries between achieving large-scale carbon dioxide removal on the one hand, and developing a truly sustainable, "circular" bioeconomy on the other. In other words, what these visions of BECCUS promise is not only-and perhaps not even-the achievement of negative GHG emissions per se. Instead, they promise a future in which the photosynthetic work of plants and trees is mobilised as the basis for establishing more synergistic, ostensibly "wasteless" interlinkages between large-scale energy generation and consumption on the one hand, and a diverse range of wider resource-intensive forms of industrial production on the other.

That the promise of BECCUS goes beyond the achievement of negative GHG emissions alone is already indicated, for example, by emergent efforts in the UK-led by Drax Group plc alongside a wider consortium of influential industrial actors - to create the "world's first net zero carbon industrial cluster by 2040" (Zero Carbon Humber, 2019, p. 4). For this consortium, investment in the necessary infrastructures to achieve BECCUS at Drax should exert a galvanising effect upon the wider economy of the Humber estuary region, not least by rendering investment in carbon capture, utilisation and storage technology in other industries-including notably in hydrogen fuel productionmore economically viable. Decisive government investment in BECCUS is thus advocated by this group as an essential means of drastically reducing the GHG emissions associated with UK electricity generation, while simultaneously helping other energyintensive industries (such as refining, petrochemicals, and steel manufacturing) to "grow in the Humber while helping to meet the UK's ambitious climate targets" (Zero Carbon Humber, 2019, p. 4). Against a backdrop formed by the economic shocks of the COVID-19 pandemic, the scenario envisaged by protagonists of this zero-carbon industrial cluster-involving tens of thousands of new jobs and the UK's transition "from a green recovery to a world-leading green industrial powerhouse" (Drax Group plc, 2020b) ${ }^{6}$-depends critically upon the switch from large-scale coal burning to large-scale biomass combustion. In other words, it is a scenario in which plants become the new prime movers of a mode of economic growth which is-for Drax Group plc. and their associates at least-truly "clean," having allegedly been

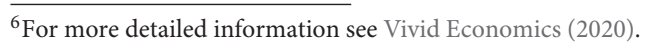


fully decoupled from the twin problems of resource depletion and climate change.

Of course, if BECCUS is ever to furnish developed economies like the UK not only with large volumes of renewable fuel, but also with large volumes of carbon dioxide from which to manufacture other commodities, the global energy sector will need to harness the photosynthetic work-or what might be termed the "vegetal labour" (Palmer, 2021)of an unprecedented quantity of plants. Indeed, BECCUS scenarios like those being outlined by Drax and other industrial stakeholders in the UK today would arguably require the establishment, at the planetary scale, of an explicitly multispecies regime of "circular" carbon metabolism-a regime in which the vital capacities of vegetal lifeforms would not only be more extensively harnessed than ever before, but also deliberately augmented by human scientific, technological and engineering capabilities ${ }^{7}$.

Whether or not BECCUS eventually does come to fruition at such a vast scale, visions of the technology being articulated by key industrial stakeholders are discursively powerful, we argue, in that they reinforce deeply-ingrained understandingsdeveloped initially in the era of fossil fuels-of intensive energy consumption as a virtuous act (Daggett, 2019), in the process marginalising alternative visions that frame limits on, or absolute reductions in energy use, as desirable. In the nineteenth-century, of course, the supposedly universal economic and societal benefits associated with the industrial revolution were predicated ultimately on the increasingly efficient and productive use of fossil fuels. Depictions of BECCUS as desirable, by contrast, hinge on the idea that economic growth and climate repair can be reconciled-again, with purportedly universal benefits-by more intensively harnessing the theoretically inexhaustible energetic potential of plants.

\section{GOVERNING CARBON DIOXIDE REMOVAL: BEYOND MERE NEGATIVE EMISSIONS}

Simply by promising to achieve vast quantities of negative GHG emissions, carbon dioxide removal technologies of various kinds are already serving to postpone the point at which large-scale fossil fuel burning will become economically unviable. At least in part, enthusiasm for CDR can already be viewed as "the mobilisation of a specific vision of the future as a way to legitimise and reproduce the present" (Carton, 2019, p. 764). In this Perspective, we have sought to show how BECCS specifically risks "reproducing" the present in a still more fundamental sense, by perpetuating a thoroughly nineteenth-century, north-west European understanding of the purpose of energy itself, one in which the large-scale, centralised combustion of hydrocarbonbased fuels is sanctioned as a force for (purportedly) universal economic growth and wider societal benefit. In scrutinising the

\footnotetext{
${ }^{7}$ Note that the appeal and possibility of "circular carbon" is not exclusive to BECCUS. It is present in visions of other proposed negative emission technologies as well, most notably Direct Air Capture (see Malm and Carton, 2021).
}

ongoing efforts of influential UK energy stakeholders to promote not just BECCS, but BECCUS, we have moreover argued that a potential turn to carbon utilisation would serve not just to render bioenergy-based negative GHG emissions more economically viable, but also to actively blur the boundaries between large-scale carbon dioxide removal on the one hand, and the realisation of a circular bioeconomy on the other. At the core of these prominent visions of BECCUS is not just the promise of decarbonisation, nor even of negative GHG emissions per se, but rather the promise of new regimes of carbon metabolism in which humans and plants work collectively to reconfigure large-scale energy generation and consumption, and indeed continued economic growth itself, into tools of climate repair. BECCUS can in this sense be viewed as the latest, optimised incarnation of longerstanding attempts to mobilise modern, large-scale bioenergy production as a "fix" for the socio-ecological contradictions not strictly of energy use, but rather of fossil fuel-based capitalism as a whole (Carton, 2019; Palmer, 2021).

Importantly, when BECCUS is viewed as global-scale project for reconfiguring the very flows of carbon upon which future, ostensibly "clean" economic growth can be predicated, many of the objections typically raised by the technology's opponents are effectively diffused and delegitimised à priori. Concerns relating for example to the impacts of increased biomass cultivation upon biodiversity, soil and water quality, food security, or even land rights (Schlesinger, 2018) - not to mention GHG emissions associated with land-use change-all appear from this perspective as products of particular but ultimately curable instances of ineffective implementation ${ }^{8}$, rather than universal objections to the internal logic of BECCUS itself. Reckoning with what might be termed the "properly political" dimensions (Swyngedouw, 2009) of BECCUS will therefore require governance processes for $\mathrm{CDR}$ as a whole to go beyond assessments of the technical efficiency and "on-the-ground" impacts of diverse approaches to achieving negative emissions in practice-however ostensibly encouraging or discouraging those forms of assessment may be. Appraising BECCUS, and indeed adjudicating between other carbon dioxide removal technologies and systems, ultimately also needs to involve a societal discussion about the kind of energy futures that such technologies represent and the selective ideas of human progress implied within them.

Among the most fundamental questions to be deliberated here, perhaps, is what should be allowed to count as a desirable or useful form of energy consumption in the twenty-firstcentury. A satisfactory answer to this question is unlikely to emerge without also confronting the deeply uneven geographies of energy supply and consumption which are implied by the kind of visions of BECCUS being articulated by key industrial stakeholders in the UK today. Indeed, if carbon dioxide removal technologies are allowed to reinforce nineteenth-century ideas about the inevitably universal societal benefits of large-scale energy consumption, then they risk reinscribing, rather than

\footnotetext{
${ }^{8}$ The prodigious rise of sustainability certification schemes for biofuels and other bio-based commodities are an obvious product of this perspective-the problem is located at the level of particular supply chains, rather than with the internal logic of massive bioenergy expansion per se.
} 
unpicking, a damaging set of interconnections forged between industrial production and imperialist plunder in the fossil fuel era. Partly replacing coal, oil and gas with biomass will inevitably reshape global energy geographies, but whether it will restructure them-in ways that prevent distant locales from being enrolled as the peripheral resource hinterlands for existing centres of global wealth and power-is another question altogether. In view of these uneven geographies, fully opening up the question of what energy consumption should be for in the coming decades will arguably require a reconfiguration of existing carbon dioxide removal governance processes, to facilitate greater dialogue and more even participation on the part of stakeholders and citizens in both high energy consuming and low energy consuming regions.

Amid the growing clamour to pursue large-scale negative emissions systems as a means of meeting net-zero GHG emissions targets in contexts like the UK, there is a danger associated with developing governance processes and institutions focused solely on comparing the technical "performance" and on-the-ground social and environmental consequences of various forms of carbon dioxide removal. It would be a missed opportunity to pursue carbon dioxide removal without explicit societal deliberation about the range of alternative energy futures that are possible in a post-fossil fuel era. A key role for CDR governance should be to enable these kinds of choices. In short, if ongoing CDR efforts are to be successful, they will need to achieve the removal of emissions of carbon dioxide in two senses-not only physically, from the global atmosphere, but also politically, from their position

\section{REFERENCES}

Bellamy, R., Fridahl, M., Lezaun, J., Palmer, J., Rodriguez, E., Lefvert, A., et al. (2021). Incentivising bioenergy with carbon capture and storage responsibly: comparing stakeholder responses in the United Kingdom and Sweden. Environ. Sci. Policy 116, 47-55. doi: 10.1016/j.envsci.2020. 09.022

Carton, W. (2019). "Fixing" climate change by mortgaging the future: negative emissions, spatiotemporal fixes, and the political economy of delay. Antipode 51, 750-769. doi: 10.1111/anti.12532

Chatham House (2020). Net Zero and Beyond: What Role for Bioenergy With Carbon Capture and Storage?

Committee on Climate Change (2019). Net Zero: The UK's Contribution to Stopping Global Warming.

Cook-Patton, S. C., Leavitt, S. M., Gibbs, D., Harris, N. L., Lister, K., and Anderson-Teixeira, K. J., et al. (2020). Mapping carbon accumulation potential from global natural forest regrowth. Nature 585, 545-550. doi: 10.1038/s41586-020-2686-x

Daggett, C. (2019). The Birth of Energy: Fossil Fuels, Thermodynamics, and the Politics of Work. Durham, NC: Duke University Press.

Drax Group plc (2018). What Can Be Made From Captured Carbon?'. Available online at: https://www.drax.com/technology/can-made-capturedcarbon/ (accessed May 28, 2021).

Drax Group plc (2019a). Carbon Dioxide Now Being Captured in First of its Kind BECCS Pilot. Available online at: https://www.drax.com/press_release/worldfirst-co2-beccs-ccus/ (accessed May 28, 2021).

Drax Group plc (2019b). New Carbon Capture Technology Could Help Industry and Agricultural Sector Decarbonize. Available online at: https://www.drax.com/ press_release/new-carbon-capture-technology-help-industry-agriculturalsector-decarbonise/ (accessed May 28, 2021). as principal (if not sole) indicators by which the wider desirability of societal development pathways is determined. Only by recognising large-scale carbon dioxide removal as a project concerned with far more than mere negative emissionswith more even than the issue of climate change itselfcan relevant governance processes hope to cultivate genuinely post-fossil ideas about what "good" energy use might look like, and indeed about how else societal virtue might be defined, over the course of the remainder of the twentyfirst century.

\section{DATA AVAILABILITY STATEMENT}

The original contributions presented in the study are included in the article, further inquiries can be directed to the corresponding author/s.

\section{AUTHOR CONTRIBUTIONS}

JP wrote the first draft of the manuscript. JP and WC contributed to manuscript revision, read, and approved the submitted version. Both authors contributed to the article and approved the submitted version.

\section{FUNDING}

The article builds on research undertaken by JP and funded by the University of Bristol's Vice-Chancellor's Fellowship scheme.

Drax Group plc (2020a). Negative Emissions Pioneer Drax and Leading Global Carbon Capture Company - Mitsubishi Heavy Industries Group - Announce New BECCS Pilot. Available online at: https://www.drax.com/press_release/ negative-emissions-pioneer-drax-and-leading-global-carbon-capturecompany-mitsubishi-heavy-industries-group-announce-new-beccs-pilot/ (accessed May 28, 2021).

Drax Group plc (2020b). Jobs, Skills, Zero Emissions - The Economic Need for Carbon Capture at Drax. Available online at: https://www.drax.com/energypolicy/jobs-skills-zero-emissions-the-economic-need-for-carbon-captureby-drax/ (accessed May 28, 2021).

Drax Group plc (2020c). UK Tops Global Decarbonization League Amid Renewable Revolution. Available online at: https://www.drax.com/press_release/uk-topsglobal-decarbonisation-league-amid-renewable-revolution/ (accessed May 28, 2021).

Durmaz, T. (2018). The economics of CCS: why have CCS technologies not had an international breakthrough?' Renew. Sustain. Energy Rev. 95, 328-340. doi: 10.1016/j.rser.2018.07.007

Ecofys (2017). Assessing the Potential of $\mathrm{CO}_{2}$ Utilisation in the UK. London: Ecofys. Available online at: https://assets.publishing.service.gov. uk/government/uploads/system/uploads/attachment_data/file/799293/ SISUK17099AssessingCO2_utilisationUK_ReportFinal_260517v2_1_. pdf

Foulsham, G. (2016). UCLA researchers turn carbon dioxide into sustainable concrete. UCLA Newsroom, 14 ${ }^{\text {th }}$ March (2016). [https://newsroom.ucla.edu/ releases/ucla-researchers-turn-carbon-dioxide-into-sustainable-concrete]

Griscom, B. W., Adams, J., Ellis, P. W., Houghton, R. A., Lomax, G., and Miteva, D. A., et al. (2017). Natural climate solutions. Proc. Natl. Acad. Sci. 114, 11645-11650. doi: 10.1073/pnas.1710465114

Hansson, A., Fridahl, M., Anshelm, J., and Haikola, S. (2021). Boundary work and interpretations in the IPCC review process of the role of bioenergy with carbon 
capture and storage (BECCS) in limiting global warming to $1.5^{\circ} \mathrm{C}$. Front. Clim. 3:643224. doi: 10.3389/fclim.2021.643224

Hubau, W., Lewis, S., Phillips, O. L., Affum-Baffoe, K., Beeckman, H., and Cuní-Sanchez, A., et al. (2020). Asynchronous carbon sink saturation in African and Amazonian tropical forests. Nature 579, 80-87. doi: 10.1038/s41586-020-2035-0

IPCC (2014). Climate Change 2014: Mitigation of Climate Change.

IPCC (2018). Global Warming of $1.5^{\circ} \mathrm{C}$. An IPCC Special Report on the Impacts of Global Warming of $1.5^{\circ} \mathrm{C}$ Above Pre-industrial Levels and Related Global Greenhouse Gas EMISSION pathways, in the Context of Strengthening the Global Response to the Threat of Climate Change, Sustainable Development, and Efforts to Eradicate Poverty.

Jiang, Z., Xiao, T., Kuznetsov, V. L., and Edwards, P. P. (2010). Turning carbon dioxide into fuel. Philos. Trans. R. Soc. A 368, 3343-3364. doi: 10.1098/rsta.2010.0119

Lenton, T., and Latour, B. (2018). Gaia 2.0. Science 361, 1066-1068. doi: $10.1126 /$ science.aau0427

Lohmann, L. (2021). "Bioenergy, thermodynamics and inequalities," in Bioeconomy and Global Inequalities: Socio-Ecological Perspectives on Biomass Sourcing and Production, eds M. Backhouse, R. Lehmann, K. Lorenzen, M. Lühmann, J. Puder, F. Rodríguez, and A. Tittor (London: Palgrave MacMillan), 85-103.

Malm, A., and Carton, W. (2021). Seize the means of carbon removal: the political economy of direct air capture. Hist. Mater. 29, 3-48. doi: 10.1163/1569206X-29012021

Moomaw, W. R., Masino, S. A., and Faison, E. K. (2019). Intact forests in the United States: proforestation mitigates climate change and serves the greatest good. Front. Forests Glob. Change 2, 1-10. doi: 10.3389/ffgc.2019.00027

Obersteiner, M., Azar, C., Möllersten, K., and Riahi, K. (2002). Biomass Energy, Carbon Removal and Permanent Sequestration - A 'Real Option' for Managing Climate Risk. International Institute for Applied Systems Analysis Interim Report IR-02-042.

ONS (2019). A Burning Issue: Biomass is the Biggest Source of Renewable Energy Consumed in the UK. Office for National Statistics. aVAilable online at: https://www.ons.gov.uk/economy/environmentalaccounts/articles/ aburningissuebiomassisthebiggestsourceofrenewableenergyconsumedintheuk/ 2019-08-30 (accessed May 28, 2021).

Palmer, J. (2021). Putting forests to work? Enrolling vegetal labor in the socioecological fix of bioenergy resource-making. Ann. Am. Assoc. Geogr. 111, 141-156. doi: 10.1080/24694452.2020.1749022

Royal Society and Royal Academy of Engineering (2018). Greenhouse Gas Removal.

Schlesinger, W. (2018). Are wood pellets a green fuel?' Science 359, 1328-1329. doi: $10.1126 /$ science.aat 2305

Scott, V., Gilfillan, S., Markusson, N., Chalmers, H., and Haszeldine, R. S. (2013). Last chance for carbon capture and storage. Nat. Clim. Change 3, 105-111. doi: 10.1038/nclimat e1695

Searchinger, T. D., Beringer, T., Holtsmark, B., Kammen, D. M., Lambin, E. F., Lucht, W., et al. (2018). Europe's renewable energy directive poised to harm global forests. Nat. Commun. 9:3741. doi: 10.1038/s41467-018-0 6175-4

Seidl, R., Schelhaas, M.-J., Rammer, W., and Verkerk, P. J. (2014). Increasing forest disturbances in Europe and their impact on carbon storage. Nat. Clim. Change 4, 806-810. doi: 10.1038/nclimate2318

Sieferle, R. P. (2001). The Subterranean Forest: Energy Systems and the Industrial Revolution. Cambridge: White Horse Press.

Smith, P., and Porter, J. (2018). Bioenergy in the IPCC assessments. GCB Bioenergy 10, 428-431. doi: 10.1111/gcbb.12514

Swyngedouw, E. (2009). The antinomies of the postpolitical city: in search of a democratic politics of environmental production. Int. J. Urban Reg. Res. 33, 601-620. doi: 10.1111/j.1468-2427.2009.00859.x

UK DfT (2020). Renewable Fuel Statistics 2019: Final Report. UK Department for Transport, London. Available online at: https://assets.publishing.service. gov.uk/government/uploads/system/uploads/attachment_data/file/932933/ renewable-fuel-statistics-2019-final-report.pdf

USDA Foreign Agricultural Service (2019). Global Agricultural Information Network Report: EU Biofuels Annual, 2019. GAIN Report Number NL9022.

van Ypersele, J.-P. (2021). It's Time to End Subsidies for Burning Wood From Forests. Climate Home News. Available online at: https://www. climatechangenews.com/2021/02/11/time-end-subsidies-burning-woodforests/ (accessed May 28, 2021).

Varinsky, D. (2016). An Energy Company Just Debuted a Shoe Made From Power Plant Emissions. Business Insider. Available online at: https://www. businessinsider.in/An-energy-company-just-debuted-a-shoe-made-frompower-plant-emissions/articleshow/54368673.cms (accessed May 28, 2021).

Vivid Economics (2020). Capturing Carbon at Drax: Delivering Jobs, Clean Growth and Levelling Up the Humber. Vivid Economics, London. Available online at: https://www.vivideconomics.com/wp-content/uploads/2020/11/ Capturing-Carbon-at-Drax-Delivering-Jobs-Clean-Growth- and-LevellingUp-the-Humber.pdf

Zero Carbon Humber (2019). Capture for Growth-A Roadmap for the World's First Zero Carbon Industrial Cluster. Available online at: https://www.drax.com/ wp-content/uploads/2019/11/Capture-for-Growth-Zero-Carbon-HumberV4.9-Digital.pdf (accessed May 28, 2021).

Conflict of Interest: The authors declare that the research was conducted in the absence of any commercial or financial relationships that could be construed as a potential conflict of interest.

The reviewer SH declared a past co-authorship with one of the authors JP to the handling Editor.

Copyright $\odot 2021$ Palmer and Carton. This is an open-access article distributed under the terms of the Creative Commons Attribution License (CC BY). The use, distribution or reproduction in other forums is permitted, provided the original author(s) and the copyright owner(s) are credited and that the original publication in this journal is cited, in accordance with accepted academic practice. No use, distribution or reproduction is permitted which does not comply with these terms. 